\title{
Thanks for Nothing? Not-for-Profits and Motivated Agents
}

\author{
Maitreesh Ghatak ${ }^{*}$
}

And

Hannes Mueller ${ }^{\dagger}$

November 2009

The Suntory Centre

Suntory and Toyota International Centres for Economics and Related Disciplines

London School of Economics and Political Science Houghton Street

London WC2A 2AE

EOPP 14

Tel: (020) 79556674

\footnotetext{
* Department of Economics, R530; London School of Economics; Houghton Street; London WC2A 2AE; United Kingdom. Tel: +44 (0) 207-852-3568. Email: m.ghatak@lse.ac.uk

${ }^{\dagger}$ Institut d.Analisi Economica, CSIC; Campus UAB; 08193, Bellaterra (Barcelona); Spain. Tel: 0034 935929774. Email: hannes.mueller@iae.csic.es.
} 


\begin{abstract}
We re-examine the labor donation theory of not-for-profits and show that these organizations may exist not necessarily because motivated workers prefer to work in them, or that they dominate for-profits in terms of welfare, but because the excess supply of motivated workers makes the non-profit form more attractive to managers. We show that if firms had to compete for motivated workers then not-forprofit firms would be competed out by for-profit firms. Therefore, the choice between not-for-profit and for-profit provision is not always a question of resolving incentive problems but also one of distribution of rents between management and workers, and consequently, the relative scarcity of workers plays an important role in this choice.
\end{abstract}

Keywords: not-for-profits, intrinsic motivation, labor donation, free riding

JEL Codes: L31, J32, L33, J42, 
This series is published by the Economic Organisation and Public Policy Programme (EOPP) located within the Suntory and Toyota International Centres for Economics and Related Disciplines (STICERD) at the London School of Economics and Political Science. This new series is an amalgamation of the Development Economics Discussion Papers and the Political Economy and Public Policy Discussion Papers. The programme was established in October 1998 as a successor to the Development Economics Research Programme. The work of the programme is mainly in the fields of development economics, public economics and political economy. It is directed by Maitreesh Ghatak. Oriana Bandiera, Robin Burgess, and Andrea Prat serve as codirectors, and associated faculty consist of Timothy Besley, Jean-Paul Faguet, Henrik Kleven, Valentino Larcinese, Gerard Padro i Miquel, Torsten Persson, Nicholas Stern, and Daniel M. Sturm. Further details about the programme and its work can be viewed on our web site at http://sticerd.lse.ac.uk/research/eopp.

Our Discussion Paper series is available to download at:

http://sticerd.lse.ac.uk/_new/publications/series.asp?prog=EOPP

For any other information relating to this series please contact Leila Alberici on:

Telephone: UK+20 79556674

Fax: $\quad$ UK+20 $\quad$ : $\quad$ (a556951

Email: $\quad$ l.alberici @lse.ac.uk

(c) The authors. All rights reserved. Short sections of text, not to exceed two paragraphs, may be quoted without explicit permission provided that full credit, including (C) notice, is given to the source. 


\section{Introduction}

The strength of the not-for-profit sector has long puzzled economists in the light of the basic assumption that financial incentives are an important engine of economic activity in a market economy. ${ }^{1}$ The existing view of notfor-profits is that they are a second-best response to certain types of incentive problems. $^{2}$ One set of theories focus on contract failure (Hansmann, 1980) and argue that the not-for-profit status enables the management to commit to a higher level of quality or to ensure that donated money or labor will not be appropriated for private gain (e.g., Easely and O'Hara, 1983, Glaeser and Shleifer, 2001, and Bilodeau and Slivinski, 2004). Another set of theories (see, Francois, 2000, and 2003) focus on free-riding within a firm and argue that the not-for-status might be a credible commitment device on the part of the management to supply less effort than in a for-profit firm, thereby inducing greater labor donation from intrinsically motivated workers. Both sets of theories of not-for-profits either show or implicitly assume that they are a welfare-enhancing institution.

In this paper we re-examine the labor donation theory of not-for-profits based on free-riding, and show that it suggests an alternative, somewhat darker view of not-for-profits. The starting point of the labor donation theory is that not-for-profits tend to be concentrated in activities that have a public good element, and that volunteering is an important source of labor in these organizations. ${ }^{3}$ We show that not-for-profit organizations may exist in these activities because the excess supply of motivated workers makes the

\footnotetext{
${ }^{1} \mathrm{~A}$ study of 26 countries conducted in the mid 1990s (Salamon et al, 1999), for example, found that not-for-profits employed an average 6.8 percent of the non-agricultural workforce ( $12 \%$ in the case of the US). Another study of eight OECD countries about a decade later (Salamon et al, 2007) show that not-for-profits contributed $8 \%$ to the GDP on average $(7.2 \%$ in the case of the US).

${ }^{2}$ See Rose-Ackerman (1996) and Francois and Vlassopoulos (2008) for excellent surveys of the literature.

${ }^{3}$ Health, education, and social services account for $61 \%$ of the contribution of not-forprofits to GDP on average in the eight countries studied by Salamon et al (2007). About half of the 14 million full-time employees in the US not-for-profit sector work on voluntary basis and volunteer time accounts for about a quarter of not-for-profit contribution to GDP on average in the seven countries studied by Salamon et al (2007).
} 
non-profit form more attractive to managers without any concomitant gain in welfare compared to for-profits. The choice between not-for-profit and forprofit provision is therefore not only a question of resolving incentive problems but also one of distribution of rents between management and workers. We then proceed to embed the choice of for-profits vs. not-for-profits in a labor market setting where firms and workers match endogenously. We show that if motivated workers are scarce then competition for them would lead for-profit firms to drive away not-for-profit firms. We also show that if managers are sufficiently motivated, either financially or intrinsically, they will switch to for-profits. Similarly, if workers are very motivated then managers will prefer for-profits, the same as if the workers are not motivated at all.

Our goal is not to argue that not-for-profits are undesirable but to highlight a particular effect that strikes a cautionary note on thinking about their welfare consequences. The labor donation theory based on free riding and the theories based on contract failure suggest distinct but not mutually exclusive mechanisms. In a model that combines both, the negative welfare results will be mitigated.

Our analysis also highlights the importance of understanding organizational choice between for-profits and not-for-profits in a (labor) market setting and has several empirical implications. For example, it suggests that the importance of not-for-profits relative to for-profits within a sector would depend on, among other things, the relative scarcity of workers. Also, it implies that measures of labor market slackness (e.g., the unemployment rate) might be an important omitted variable to reckon with in studies that look at the effect of not-for-profit status on wages and labor donations.

Our paper starts off with a model of organizational choice similar to Francois (2003). The basic assumption is that both managers and workers are intrinsically motivated by the success of the project. Effort by either of the two leads to a successful outcome and the worker moves first. This gives rise to a free-rider problem in the firm, as long as the manager has an incentive to exert effort when the worker did not do so yet. The choice of not-for-profit status by the owner/manager of a firm can then be understood 
as an attempt to resolve the arising free-rider problem within the firm.

Not-for-profit status is chosen because it reduces financial incentives for the management and commits it to non-provision of the public good. This commitment guarantees workers that their individual contribution will make a difference in provision and allows managers to reduce the wage payment. The resulting gain can compensate the manager for lost profits and makes the not-for-profit an attractive choice for the manager. In other words, the not-for-profit status is chosen for projects that are financially not too beneficial because it makes more effective use of the worker's intrinsic benefits from public good provision.

However, we show that the adoption of not-for-profit status by the manager increases the burden for the worker. If worker-manager matches arise endogenously in a labor market, not-for-profit firms can only compete with for-profit firms when there is an oversupply of motivated labor. If labor is scarce, not-for-profits are crowded out. This finding provides a new possible explanation for the association between volunteer labor and not-for-profit status, namely, the abundance of motivated labor in some sectors.

If both for-profits and not-for-profits are feasible we show that not-forprofits are (weakly) dominated by for-profits in terms of welfare. This result is even stronger if we introduce some uncertainty and projects can fail with some probability even if either the worker or the manager supplies effort.

An important feature of the model is that organizational choice only affects the distribution of rents within the firm but not the nature of production. We assume that intrinsic motivation is output-based where output is single-dimensional and there is no second dimension like consumer welfare or quality. This implies that financial incentives do not harm consumer or donor welfare - whoever benefits from the project just cares about project success. We do not do this because we think it is particularly realistic but in order to separate out the labor donation theory based on free riding from the contract failure literature in a clear-cut way.

This article is structured as follows. We discuss the related literature in greater detail in section 2 . Section 3 presents the model in two steps. In sections 3.1 we lay down the basic framework, and in section 3.2 we analyze 
the case of exogenous matching between workers and managers to derive the basic mechanism by which not-for-profits can arise. In section 3.3 we discuss endogenous matching to show the effects of labor scarcity on organizational choice. The welfare implications of not-for-profit provision are discussed in section 3.4. Section 4 presents an extension. We show that the commitment of the manager to no effort via the not-for-profit status is likely to come with a strict cost in terms of welfare if production has a stochastic element. Section 5 discusses some empirical implications of our findings, and section 6 concludes.

\section{Related Literature}

The key idea behind the contract failure literature is that by limiting monetary incentives for owners not-for-profits enable the managers to commit to higher quality (e.g., if there is an underlying cost-quality trade-off) and/or attract key inputs from others (e.g., donations, labor). Hansmann (1980) provides a brief analysis of the role of not-for-profits in signalling and screening managers who vary (unobservably) in terms of how much weight they put on money versus the output of the organization. Easely and O'Hara (1983) model a society that is interested in maximizing welfare. The basic conflict in their framework is between the manager of a firm and consumers of firm output. They show that when output cannot be observed by society then managers have the incentive to raise their own utility and delivering less to the consumers. The nondistribution constraint works as a simple constraint to this behavior.

Glaeser and Shleifer (2001) model the incentives of a manager who chooses between a for- and not-for-profit setting. They argue that profit incentives might lead to undesirable outcomes from the point of view of donors who value the non-contractible outcome of the firm. Their argument is related to the multi-tasking argument of Holmstrom and Milgrom (1991). Motivating an agent on a contractible task (effort in increasing output or reducing costs) might lead to undesirable outcomes because another noncontractible task (effort in improving quality) is neglected. They show that 
not-for-profits remain attractive for managers because the reduced financial incentive in the not-for-profit is compensated by the increase in donations. ${ }^{4}$ A similar argument is made by Bilodeau and Slivinski (2004), who show that the non-distribution constraint provides the entrepreneur with a means of committing to not appropriate funds which others wish to assign to the provision of the public good, and so it induces higher donations by the public.

An important recent contribution by Francois (2000) provides a formal analysis of the theory of labor donations. He starts off with the premise that workers are intrinsically motivated in certain activities. He looks at an environment where there is a problem of moral hazard in teams or free riding within the organization. He shows that when workers receive intrinsic motivation from the provision of an output, the firm faces a public good problem. If the manager is very motivated to provide the output, he needs to pay the worker a higher wage to motivate effort because the worker knows that provision is likely even if he shirks because the manager will step in. Francois argues that this need to pay higher wages under a for-profit is the reason why the reduced financial incentives in the public sector can be attractive to a social planner, as it would reduce the wage. We follow the basic argument but show that if the for-profit is feasible it will weakly increase welfare compared to not-for-profit provision (and strictly so under some circumstances).

The idea that intrinsic motivation might lead to a wage differential between the for- and not-for-profit sector has received a fair amount of attention in empirical work. ${ }^{5}$ But there are subtle differences in how a wage differential can be interpreted. Francois (2003) argues that workers like to exert more effort in not-for-profits because not-for-profit managers have less pecuniary incentives to cut costs elsewhere. According to our model, another interpretation is that managers induce workers to accept lower wages

\footnotetext{
${ }^{4}$ Vlassopoulos (2009) show that if one introduces reputational mechanisms in the Glaeser-Shleifer framework, then for-profit status may dominate not-for-profit status.

${ }^{5}$ See, for example, Mocan and Tekin (2003), Preston (1989), Rose-Ackerman (1996), and Gregg et al (2008).
} 
through a commitment to inactivity. This interpretation suggests a gloomier picture of the not-for-profit status.

While the effect of competition in output markets on the sectorial mix has been discussed in the theoretical literature on not-for-profits ${ }^{6}$ the effect of competition for workers on organizational choice remains relatively unexplored. $^{7}$ A related paper in this respect is Besley and Ghatak (2005). In their model, mission oriented managers and workers have an interest to match with each other because this implies higher output inside the match. However, their work does not discuss the role of the nondistribution constraint in this context. The benefits from motivated agents depend entirely on the worker/manager match but are independent of the organizational form. Another related paper is Macchiavello (2008) who study the selection of motivated workers into the public vs. the private sector and the ambiguous role that high wage premium in the public sector can play.

\section{The Model}

\subsection{Basic Framework}

In this section we present a simple model of organizational choice. A firm consists of a worker $(W)$ and a manager $(M)$. For now, we take the match between the worker and the manager to be exogenously given and will consider later the consequences of how they are matched via a labor market.

The worker provides labor and the manager owns an asset that is required for production. In addition, the manager can intervene in the production process by allocating additional resources (effort) once the outcome of worker effort is observed. Before production starts, the manager chooses the firm's organizational form (i.e., choice between for-profit and not-for-profit status), sets wages, and terms of employment (e.g., the worker can be fired in the case of bad performance). The worker then accepts or rejects the offered

\footnotetext{
${ }^{6}$ See for example Lakdawalla and Philipson (2006).

${ }^{7}$ See for example Francois (2003) or Rowat and Seabright (2006) who develop arguments around the lower (efficiency) wage in the not-for-profit sector but do not discuss competition for workers.
} 
contract. In case she rejects she remains unemployed and the manager proceeds alone.

Production proceeds as follows. The worker moves first and chooses whether to work $\left(e_{W}=1\right)$ or shirk $\left(e_{W}=0\right)$ in the production of first stage output $\left(y_{1}\right)$, given by $y_{1}=e_{W}$. If she exerts effort she incurs an effort cost of 1. Both efforts are non-contractible, as in models of moral hazard in teams. The intermediate output, $y_{1}$, is observed by the manager but not by any third party. As a result, either input-based or output-based (or, piece rate) contracts are not feasible. ${ }^{8}$ If the project is in danger of failing $\left(y_{1}=0\right)$ the manager decides whether he wants to exert effort $\left(e_{M}=1\right)$ or not $\left(e_{M}=0\right)$. Second stage output is then determined by his effort choice: $y_{2}=e_{M}$. The cost of effort by the manager is $c \geq 1$ and will be discussed below in more detail. $^{9}$

Project success $\left(\max \left(y_{1}, y_{2}\right)=1\right)$ yields a financial return of $\pi$. In addition, we assume that manager and worker are intrinsically motivated. Both derive some utility from the project being successful. In particular, we assume that the output of the project is a public good to the worker and the manager. They receive a benefit of $\theta_{j}(j=W, M)$ from project success independently of their own effort and organizational form of the firm. ${ }^{10}$

As an example, we can think of a research project. If the project is successful then both the worker (a research assistant, a field worker, or a laboratory assistant) and the manager receive a positive non-pecuniary payoff because it helps society in some way. In addition, there are some financial benefits which can consist of research grants, salary increases, increased budget for the research group, or money obtained from patenting the innovation. The worker and the manager both have the skill to provide

\footnotetext{
${ }^{8}$ We show in Appendix $G$ that the main trade-offs remain in place when the manager can contract on output. We use efficiency wages for simplicity, relevance as well as comparability with the existing literature (in particular, Francois, 2000, 2003).

${ }^{9}$ In this formulation the two types of effort are substitutes (as in Francois, 2000, and 2003) and this naturally exacerbates the problem of free riding. The results go through so long as the efforts are not strong complements.

${ }^{10}$ In the terminology of Francois and Vlassopoulos (2008) we assume output-oriented altruism as opposed to action-oriented altruism.
} 
the appropriate labor input but for reasons of comparative advantage the worker is hired to do it. However, if the worker does not provide it then the manager has the choice to step in and save the project, or let it fail.

We assume that not-for-profits are characterized by a non-distribution constraint, i.e., the manager cannot take home all the profit, $\pi$, in case of project success. ${ }^{11}$ Below we follow the formulation of Glaeser and Shleifer (2001) of the non-distribution constraint. In particular, we assume that committing to a non-distribution constraint means that the manager can still capture some share of the profits $\alpha$. In their interpretation, the share $1-\alpha$ is lost because the manager's technology of capturing some of the profits is inefficient (e.g., in the form of perks) - it is equivalent to burning a fraction $1-\alpha$ of the profits. ${ }^{12}$

We allow the manager to choose any $\alpha \in[0,1]$. A not-for-profit firm is then defined by $\alpha<1$ and a for-profit firm by $\alpha=1$. We assume that the choice of $\alpha$ has no direct costs. Figure 1 summarizes the resulting game tree for the production process.

Given that the worker's effort and output is not verifiable, the manager can only pay a fixed wage, $w$. Following the efficiency wage literature, we assume that the manager can motivate the worker by threatening to fire her in case she is caught shirking as in standard efficiency wage models. Naturally, the worker will have to earn some rents for the firing threats to have bite. We assume that the worker has no liquid wealth and there is a limited liability constraint so that the worker's wage cannot be less than some minimum level (which we assume to be zero for simplicity). Otherwise, performance bonds or penalties could be used to give additional incentives. The worker is caught shirking and fired with certainty if $e_{W}=0$ and never fired if $e_{W}=1$. Let $\rho \leq 1$ denote the probability of a currently unemployed worker staying unemployed. ${ }^{13}$ Since in equilibrium workers do not shirk

\footnotetext{
${ }^{11}$ The manager could pay himself a flat wage and if output was constant, he could appropriate the profits by setting this wage to be high. If output is variable then he will not be able to appropriate the surplus with a fixed wage.

${ }^{12}$ See also Hansmann (1980, p. 873-875) for some anecdotal support for this formulation. Another possible interpretation is that the share $(1-\alpha)$ goes to the beneficiaries in some form. We discuss the welfare outcomes for both scenarios in section 3.4.

${ }^{13}$ In order to keep the model as simple as possible we assume that this probability is
} 
and are never fired, without loss of generality our analysis will focus on the one-shot payoffs of managers and workers.

Let $e_{W}^{*}$ and $e_{M}^{*}$ denote the effort choice of the worker and the manager that are induced by the choice of $\alpha$ and $w$ via the incentive-compatibility constraints of the worker and the manager (see below). Let $\bar{u}_{M}$ and $\bar{u}_{W}$ be the outside options of the manager and the worker, respectively. The manager's problem is:

$\max _{\{\alpha \in[0,1], w \geq 0\}} E U\left(e_{W}^{*}, e_{M}^{*}\right)=e_{W}^{*}\left(\alpha \pi+\theta_{M}\right)+\left(1-e_{W}^{*}\right) e_{M}^{*}\left(\alpha \pi+\theta_{M}-c\right)-w$

subject to the following constraints:

(i) the participation constraint $(\mathrm{PC})$ of the manager:

$$
E U\left(e_{W}^{*}, e_{M}^{*}\right) \geq \bar{u}_{M}
$$

(ii) the PC of the worker:

$$
\max \left(e_{W}^{*}, e_{M}^{*}\right) \theta_{W}-e_{W}^{*}+w \geq \bar{u}_{W},
$$

(iii) the incentive compatibility constraint (ICC) of the manager:

$$
e_{M}^{*}\left(\alpha, \pi, c, \theta_{M}\right)=\left\{\begin{array}{ccc}
1 & \text { if } & \alpha \pi+\theta_{M} \geq c \\
0 & & \text { otherwise }
\end{array},\right.
$$

(iv) the ICC of the worker:

$$
e_{W}^{*}\left(w, e_{M}^{*}, \theta_{W}, \beta\right)=\left\{\begin{array}{ccc}
1 & \text { if } & \frac{\theta_{W}+w-1}{1-\beta} \geq w+e_{M}^{*} \theta_{W}+\beta^{2} \frac{(1-\rho)}{1-\beta \rho} \frac{\theta_{W}+w-1}{1-\beta} \\
0 & \text { otherwise }
\end{array}\right.
$$

where $\beta<1$ is a discount factor and $\rho \leq 1$ is the worker's probability of

not affected by labor market conditions. For the same reason we assume that there is no noise in the supervision technology, and once employed a worker who does not shirk keeps his job forever (i.e., there is no chance of exogenous break up of a match). 
staying unemployed once fired. Solving out the ICC of the worker, we get

$$
w\left(e_{M}^{*}\right) \geq \max \left\{\frac{(1-\rho \beta) e_{M}^{*} \theta_{W}+(1+(1-\rho) \beta)\left(1-\theta_{W}\right)}{\beta}, 0\right\} .
$$

The manager's ICC in equation (1) states that financial plus intrinsic benefits of the project must be higher than the intervention cost $c$ for him to exert effort. The worker's ICC is derived in Appendix A. It states that the worker exerts effort if the present value of wage and intrinsic benefit from project success minus effort costs is higher than the present value of free-riding on manager effort and being fired after one period.

The PCs are given by the expected benefits of the contract $(\alpha, w)$ chosen by the manager and the respective outside options of manager and worker. For simplicity we assume for now that the manager can and will provide the public good on his own, at cost $c$. Under this assumption his outside option is:

$$
\bar{u}_{M}=\pi+\theta_{M}-c .
$$

The manager's PC can then be rewritten as

$$
e_{W}^{*}\left(\alpha \pi+\theta_{M}\right)-w+\left(1-e_{W}^{*}\right) e_{M}^{*}\left(\alpha \pi+\theta_{M}-c\right) \geq \pi+\theta_{M}-c .
$$

Since the worker has no control rights she is not able to produce anything outside the firm. In order to keep the model simple we assume that the worker does not benefit from the public good provision of the firm if she does not work in it which is a reasonable assumption if the output is not observable outside the firm. The worker's outside option is therefore

$$
\bar{u}_{W}=0 .
$$

When we allow for endogenous matching, the outside option would be the best offer made by another organization.

This gives the worker's PC: 


$$
\max \left(e_{W}^{*}, e_{M}^{*}\right) \theta_{W}-e_{W}^{*}+w \geq 0 .
$$

Throughout, in order to focus on the interesting cases, we restrict attention to parameter values that satisfy:

\section{Assumption $A 1: \pi \geq c-\theta_{M} \geq 0$.}

If $A 1$ is violated the manager is either always committed to no effort (i.e., $\left.\pi+\theta_{M}<c\right)$ or never committed to no effort $\left(\theta_{M}>c\right)$. To keep the exposition simple, for our basic results we restrict attention to the case where $\theta_{W} \leq 1$, because otherwise the non-negativity constraint on wages would start binding. We will comment on what happens in the case $\theta_{W}>1$ at the end of the following section.

\subsection{Organizational Choice}

The not-for-profit status comes at the cost of decreased rents to the manager, but with the benefit of lower wages. It will be chosen if the latter outweighs the former. This section derives necessary and sufficient conditions for this to be the case.

The key to understanding the role of not-for-profits lies in the manager ICC, namely, equation (1). The inequality shows that reducing the profit share $\alpha$ reduces the incentives of the manager to bail out a failing project because it reduces his financial benefit from project success. In other words, not-for-profit status can be used to reach commitment vis a vis the worker. If $\alpha$ is sufficiently low in the not-for-profit, the worker knows that her effort will be crucial for project success. This ability of the not-for-profit to commit the manager to no effort is crucial for its attractiveness from the perspective of the manager. If $A 1$ is violated the choice of $\alpha$ does not affect either the manager's incentives (1) or the worker's incentives (2). Since lowering $\alpha$ from 1 directly reduces the manager's utility, $\alpha<1$ is never chosen if the inequalities in $A 1$ are not fulfilled.

If $A 1$ if fulfilled, however, the manager can commit to let the project fail 
$\left(e_{M}^{*}=0\right)$ by adopting not-for-profit status. Formally, commitment is reached if the profit share satisfies:

$$
\alpha \leq \alpha^{*} \text { where } \alpha^{*} \equiv \frac{c-\theta_{M}}{\pi} .
$$

The interpretation is, the monetary benefit $\alpha \pi$ is lower than the costs over and above what the manager is compensated for by intrinsic motivation, $c-\theta_{M}$. The threshold $\alpha^{*}$ follows immediately from the manager's ICC, namely, equation (1). It is important to note that in this model the reduction of financial incentives has no direct positive effects (like increased investments or quality) but only serves as a commitment device for the manager. However, we show below that the advantage of not-for-profit status for the manager is that it might reduce wage payments.

From the worker's ICC, equation (2), the minimum wage needed to induce worker effort can be written as:

$$
w\left(e_{M}^{*}\right)=A\left(1-\theta_{W}\right)+(A-1) e_{M}^{*} \theta_{W}
$$

(because we restrict attention to $\theta_{W} \leq 1$ the non-negativity constraint never binds strictly) where

$$
A \equiv \frac{1+(1-\rho) \beta}{\beta} .
$$

Notice that, as $\beta<1$ and $\rho \leq 1, A>1$. The interpretation of $A$ is it is the efficiency wage for a worker who has no intrinsic motivation $\left(\theta_{W}=0\right)$. As the cost of effort is 1 , and the outside option is zero, $A$ has to be greater than 1 for the agent to receive any rents. The lower is $\beta$ (more impatient is the worker) and the lower is $\rho$ (the easier it is for an unemployed worker to find a job), the incentive problem is larger, and so the higher will be $A$.

Lemma 1 Assume A1 holds. Then not-for-profits with $\alpha \leq \alpha^{*}$ have to pay a smaller wage to workers to motivate worker effort $\left(e_{W}^{*}=1\right)$ than any firm with $\alpha>\alpha^{*}$, in particular, $\alpha=1$. 
Proof. For $e_{M}^{*}=0$ from (5) we get:

$$
w(0)=A\left(1-\theta_{W}\right)
$$

and for $e_{M}^{*}=1$, it is:

$$
w(1)=A-\theta_{W}
$$

As $A>1, w(0)<w(1)$ for all $1 \geq \theta_{W} \geq 0$. For the lemma to hold we also have to make sure that the worker's PC, equation (4), is satisfied. For a for-profit, $e_{W}^{*}=e_{M}^{*}=1$ and so the worker's $\mathrm{PC}$ is $\theta_{W}+w(1) \geq 1$. As $A>1$ this is satisfied. Similarly, for a not-for-profit, $e_{W}^{*}=1$ and $e_{M}^{*}=0$ and so the worker's $\mathrm{PC}$ is $\theta_{W}+w(0) \geq 1$, or, $A\left(1-\theta_{W}\right)+\theta_{W} \geq 1$. As $A>1$, and $\theta_{W} \leq 1$, this is satisfied. Now the proof follows from the fact that non-profits with $\alpha \leq \alpha^{*}$ commit the manager to inactivity (i.e., $e_{M}^{*}=0$ ).

Lemma 1 states that the incentive-compatible wage is lower in not-forprofits than in for-profits. The intuition is simple: if the manager is very motivated he saves the project in case it is about to fail $\left(e_{M}^{*}=1\right)$ and the worker receives $\theta_{W}$ regardless of her effort level. She is then tempted to freeride on the public good provision by the manager and a higher efficiency wage is needed to motivate her to supply effort. In the not-for-profit the manager can reduce the profit share to $\alpha^{*}$ and commit to $e_{M}^{*}=0$. This increases effort incentives for the worker because the worker now knows that without her effort the project will fail.

Henceforth we will refer to $w(0)$ as $w^{N P}$ and $w(1)$ as $w^{F P}$. Table 1 summarizes the optimal wages and profit share for for-profits and not-forprofits. The optimal profit share in the not-for-profit is $\alpha^{*}$ because any further reduction would just reduce the retained profits of the manager but would not have any impact on the wage. Table 1 shows that efficiency wages are reduced by worker intrinsic motivation both in the for and not-for-profit. However, the wage reduction is higher in the not-for-profit. ${ }^{14}$

\footnotetext{
${ }^{14}$ This is similar to the result in Besley and Ghatak (2005) that motivated workers are given less high-powered incentive schemes which results in lower expected wages, and like it, suggests that workers, if possible, would like to conceal their intrinsic motivation. We abstract from issues of observability of intrinsic motivation (or lack thereof), and consequently, the role of signalling and screening (see Benabou and Tirole, 2006 and
} 


\begin{tabular}{|r|c|c|}
\hline & Optimal Wage $(w)$ & Optimal Profit Share $(\alpha)$ \\
\hline for-profit & $w^{F P}=A-\theta_{W}$ & $\alpha^{F P}=1$ \\
\hline not-for-profit & $w^{N P}=A\left(1-\theta_{W}\right)$ & $\alpha^{*}=\frac{c-\theta_{M}}{\pi}$ \\
\hline
\end{tabular}

Table 1: Optimal Wages and Profit Shares

The payoff of the manager under a not-for-profit is $\alpha^{*} \pi+\theta_{M}-w^{N P}$ while his payoff under a for-profit is $\pi+\theta_{M}-w^{F P}$. The PCs of the manager under these two organizational forms are:

$$
\alpha^{*} \pi+\theta_{M}-w^{N P} \geq \pi+\theta_{M}-c
$$

and

$$
\pi+\theta_{M}-w^{F P} \geq \pi+\theta_{M}-c
$$

These can be rewritten as:

$$
c \geq \pi+\theta_{M}-c+w^{N P}
$$

and

$$
c \geq w^{F P} .
$$

These conditions are intuitive. They mean that the wage in the not-forprofit plus the profit lost due to not-for-profit status needs to be smaller than the effort cost for the manager in autarchy. In the for-profit the wage has to be smaller than the manager's cost of effort. Substituting values of $w^{N P}$ and $w^{F P}$ these can be simplified to:

$$
\begin{aligned}
& c \geq \frac{\pi+\theta_{M}+A\left(1-\theta_{W}\right)}{2} \\
& c \geq A-\theta_{W} .
\end{aligned}
$$

Now we turn to characterizing conditions when a not-for-profit will be Delfgaauw and Dur, 2008) 
chosen. We make the following assumption:

$$
\text { Assumption } A 2: c \geq \frac{\pi+\theta_{M}}{2} .
$$

This is a necessary condition for not-for-profits to satisfy the manager's PC. If $c$ is too low relative to the project benefits then the manager will never find it attractive to choose the not-for-profit and will prefer autarchy.

Now we characterize conditions under which the trade-off between reduced financial return and reduced wages can lead to not-for-profits being preferred to for-profits:

Proposition 1 Assume $A 1$ and A2 hold. The manager prefers the not-forprofit to a for-profit if and only if

$$
\theta_{W} \geq \max \left(\frac{\pi+\theta_{M}-c}{A-1}, 1+\frac{\pi+\theta_{M}-2 c}{A}\right)
$$

However, workers never prefer the not-for-profit to a for-profit because the not-for-profit wage is lower.

Proof. See the appendix.

The intuition to the first part of the proposition is simple. If worker intrinsic motivation is high, the manager benefits from a not-for-profit because it reduces wages substantially. The loss of profit from adopting the not-for-profit status relative to the for-profit status is $\left(1-\alpha^{*}\right) \pi$, which can be rewritten $\pi+\theta_{M}-c$. In other words, not-for-profit status leads to a bigger loss if the project is very attractive from the manager's point of view. Therefore, the manager prefers the not-for-profit to the for-profit if his financial and intrinsic benefits from the project are not too high relative to the intrinsic motivation of the worker.

The worker's preference for the for-profit is surprising given the usual perception that intrinsically motivated workers prefer not-for-profit firms. In our model, under both the for-profit and the not-for-profit, the output is the same but the former pays a higher wage. Effectively, in not-for-profit 
firms, the manager free rides on the intrinsically motivated worker. ${ }^{15}$

This highlights an important difference to other models in the literature which derive not-for-profit status from contractual failure vis a vis the beneficiary. The difference becomes clear if we re-interpret the worker as a donor. In our model, the not-for-profit is a commitment device by the manager to stay inactive if the donor does not donate to the firm. This commitment increases donations but does not necessarily improve the welfare of the beneficiary. If the donor could choose he would donate to a for-profit.

Notice that our result is driven by the fact that managers will produce the public good even if they do not find a motivated worker, which is ensured by Assumption $A 1$. It might seem that this biases the choice against notfor-profits. But if $A 1$ does not hold, then not-for-profits cannot exist as the manager is either always committed to no effort or always committed to supply effort.

Our framework allows us to examine the effects of changes in manager and worker motivation on organizational choice very clearly.

By $A 1$ the existence of a not-for-profit industry generally depends on a relatively low level of intrinsic benefits $\theta_{M}$. If $\theta_{M}>c$, Assumption $A 1$ is violated and the not-for-profit looses its ability to commit the manager to no effort. As a result, for-profits are always chosen. On the other hand, if $\theta_{M}=0$, not-for-profits can exist so long as the conditions in Proposition 1 are satisfied. Also, keeping total profitability $\left(\pi+\theta_{M}\right)$ constant, not-forprofits are less likely with more motivated managers. We summarize this as:

Observation 1 The greater is the intrinsic motivation of the manager $\left(\theta_{M}\right)$ the less likely not-for-profits will be the chosen organizational form.

The intuition is simple. Since the key issue is free-riding, if the manager is very motivated, he cannot commit not to work on the project in case the worker shirks. But then there is no point in making costly organizational

\footnotetext{
${ }^{15}$ This relies on the assumption that the intrinsic motivation $\theta_{W}$ is the same in both cases. If motivation is not observable then working in a not-for-profit for a low wage could serve as a signal that one is pro-social (as in Benabou and Tirole, 2006).
} 
choices in order to try to commit. This provides a theory of the choice between for-profit social enterprises and not-for-profits. Social enterprises can be organized as either for-profits or not-for-profits and combine a revenue generating business with a social value generating component. They pursue what is often referred to as a double bottom-line which is a combination of profit and mission-related impact. It is argued that revenue generation allows social enterprises to be self-sustaining and profits attract additional capital to solve social ills. ${ }^{16}$

Next we turn to worker motivation. Clearly, if workers are unmotivated $\left(\theta_{W}=0\right)$ then not-for-profits will never be chosen. Proposition 1 shows that worker motivation will have to exceed some positive threshold for notfor-profits to become an attractive option. What happens if workers are very motivated? Recall that so far we have restricted attention to $\theta_{W} \leq 1$ to keep the exposition simple. Suppose $A>\theta_{W}>1$. Now $w^{N P}=0$ but $w^{F P}=A-\theta_{W}>0$. Therefore, inserting these in the condition for not-forprofits to be chosen, i.e., $w^{F P}-w^{N P} \geq \pi+\theta_{M}-c$, we get

$$
\theta_{W} \leq A-\left(\pi+\theta_{M}-c\right)
$$

In other words, if the worker is very motivated then for-profits become attractive relative to not-for-profits, because the former allows the manager to benefit more from extra worker motivation through lower wages than the latter, where the wage hits a lower bound. If $\theta_{W}>A$, then $w^{N P}=w^{F P}=0$ and for-profits will always be chosen. This is intuitive, because the only reason to choose not-for-profits in our framework (which is costly to the manager in the form of having to give up full residual claimancy) is it can yield lower wages. If both for-profit and not-for-profit wages are equal, then for-profits will be preferred. We summarize this as:

Observation 2 If the worker has very low or very high intrinsic motivation then for-profits will be preferred by the manager. Not-for-profits can arise only for intermediate levels of worker motivation.

\footnotetext{
${ }^{16}$ See Martin and Osberg (2007) and Bornstein (2004).
} 
We will see in the next section that another force that could lead to forprofits and not-for-profits to have equal wages is labor market competition for motivated workers and this too would lead the former being preferred to the latter.

So far we assumed that due to a limited liability constraint, the worker has to be paid non-negative wages. In some settings this may not be a good assumption. There are instances where volunteers or interns pay a fee to serve in an organization. Recall that in our model not-for-profit and forprofit wages are $A\left(1-\theta_{W}\right)$ and $A-\theta_{W}$ respectively. Clearly, for $\theta_{W}>1$, both wages are negative and the former is less than the latter as $A>1$.

Observation 3 If there is no limited liability constraint and the worker can be charged a fee to serve in the organization, not-for-profits would charge a higher fee than for-profits.

Intuitively, both for-profits and not-for-profits charge the worker for her participation in the industry. The worker is willing to pay because unemployment would exclude her from intrinsic benefits derived from the project. Under a for-profit the manager cannot commit not to supply effort if the worker does not, and this means the worker will have to be paid a greater premium to supply effort compared to a not-for-profit, which in this case, translates into a lower fee that the worker can be charged. The not-forprofit can charge more because it commits the manager to inactivity. An example might illustrate this point. There is a quickly growing industry of volunteer tourism which combines typical backpacking trips with development work. In this sector, not-for-profit firms provide local development work for the traveler. Most of the field work requires only unskilled labor, available in abundance in the local community. Still, volunteers are intrinsically so motivated that they are willing to pay the organization to get work. The web-sites organizing the market strongly suggest that the impact of the volunteer is an important consideration for this willingness to pay. ${ }^{17}$ In other words, the labor market features payments from the worker

\footnotetext{
${ }^{17}$ Volunteer travel, or "voluntourism" has become quite popular which combines travel with volunteering for a charitable cause.
} 
to the organization (a negative wage) in return for the opportunity to make a difference.

\subsection{Labor Markets and Organizational Choice}

This section extends the model derived in the previous section to a labor market setting where a number of workers and managers match endogenously. The aim of this exercise is to show that labor market conditions and organizational choice are closely linked, a point that existing theories of not-for-profits have ignored.

Assume that there are $M$ managers with intrinsic motivation $\theta_{M} \geq 0$, $N_{m}$ motivated workers with $\theta_{W}>0$ and $N_{u}$ unmotivated or neutral workers with $\theta_{W}=0$. In what follows we assume that there is some unemployment, $N_{u}+N_{m}>M$. However, we will allow the degree to which motivated workers are scarce to vary, i.e., $N_{m} \gtrless M$.

At the matching stage managers choose a contract $(\alpha, w)$ to maximize their expected utility $E U\left(e_{W}^{*}, e_{M}^{*}\right)$ subject to the PC of themselves and that of the worker. A stable matching is one where no change of match could strictly increase a manager's or worker's utility without making the new matching partner worse off compared to how she was before. Production takes place once a stable matching is reached.

A crucial question for the effect of the labor market on organizational choice is whether the for-profit organizational form can satisfy the manager's PC. Assume first that for-profits are feasible in the sense that the manager always prefers to be in a for-profit than to produce alone.

Proposition 2 Assume $A 1$ and that for-profit provision is feasible, i.e., $c \geq A-\theta_{W}$. If motivated labor is scarce $\left(N_{m}<M\right)$ then not-for-profit firms cannot exist in labor market equilibrium.

Proof. We prove the proposition by contradiction. Assume that there are some not-for-profits in a matching equilibrium with $N_{m}<M$. First, note that by Proposition 1 workers prefer to work in for-profits. As motivated workers are scarce $\left(N_{m}<M\right)$ there are some managers who are matched 
with an unmotivated worker. These managers will always set up for-profit firms because not-for-profit status does not reduce their wage bill, $w=$ A. A worker in a not-for-profit firm can therefore improve her position by replacing an unmotivated worker in a for-profit match. The manager will accept this swap because he prefers a for-profit match with a motivated worker to a for-profit match with an unmotivated worker.

An immediate corollary is:

Corollary 1 Assume $A 1$ and that for-profit provision is feasible, $c \geq A-$ $\theta_{W}$. If motivated workers are abundant $\left(N_{m}>M\right)$ then not-for-profits can exist in labor market equilibrium and Proposition 1 applies.

Proposition 2 provides a pessimistic view of not-for-profit firms. It states that if the adoption of not-for-profit status is motivated by the desire to use intrinsic motivation of workers to reduce wages then a slack labor market is a necessary condition for this to be feasible. The reason is simply that given a choice, workers always want to work for a higher wage. As we showed in the previous section, the incentive-compatible wage rate is lower in a notfor-profit than in a for-profit. In a labor surplus situation, not-for-profits can therefore exist. But in a labor-scarce situation, only the higher wage rate is relevant and so not-for-profits will be crowded out of the market by for-profits.

An important insight from this result is that the choice between not-forprofit and for-profit provision is not always a question of resolving incentive problems but also one of distribution of rents. In both organizational forms the worker provides the good at effort cost of 1 . The only difference is the wage that the manager has to pay to the worker. From this point of view, the not-for-profit is a method of redistributing rents towards the manager of the firm.

Therefore, our analysis suggests that organizational choice would depend on, among other things, the relative scarcity of workers and managers. If workers are abundant then managers can choose their preferred organizational form as if they were matched exogenously with a worker. Under $A 1$ and $A 2$ this situation is captured by condition (8). Not-for-profits are 
chosen when the wage reduction compensates the manager for the reduced financial gains. Workers have to swallow the resulting reduction in wages because there is an oversupply of motivated labor.

So far we have compared the not-for-profit status directly with the forprofit status. The picture changes somewhat if managers prefer working alone to setting up for-profit firms.

Proposition 3 Assume $A 1$ and A2. Regardless of the relative scarcity of managers and workers $\left(M \gtreqless N_{m}\right)$ there is a not-for-profit sector if the manager's PC can be satisfied in the not-for-profit but not in the for-profit, i.e. if

$$
A-c \geq \theta_{W} \geq 1+\frac{\pi+\theta_{M}-2 c}{A}
$$

Proof. See the appendix.

According to Proposition 3 not-for-profits could play a role in industries that are not attractive to for-profit firms. The reason is that not-for-profits lead to a redistribution of rents toward owners of assets and can therefore make setting up a firm easier. The conditions in the proposition indicate that not-for-profits arise as long as the available projects are not too attractive (both in terms of pecuniary and non-pecuniary returns) for the manager and for intermediate values of worker intrinsic motivation.

An interesting comparative static result that follows directly from Propositions 2 and 3 is that, as $c$ rises for-profits can become feasible, and an industry that produces public goods might change from not-for-profit provision to for-profit provision. If we interpret $c$ as the level of specialization in the labor force, not-for-profits will be most common in industries that combine high level of worker intrinsic motivation with a low level of specialization. ${ }^{18}$

\footnotetext{
${ }^{18}$ This comparative static is partly supported by a survey among 1900 persons responsible for human resources (HR) in the voluntary sector in England (Clark (2007)). The study shows that vacancies which require specific skills were most likely to be categorized as hard to fill by the HR personal. It is not clear, however, whether this was due to general scarcities or a not-for-profit phenomena.
} 


\subsection{Welfare}

So far we have focused on the choice between not-for-profits and for-profits from the point of view of the manager. In this section we discuss the welfare implications. In order to keep the focus on the comparison between not-forprofits and for-profits we assume throughout that the manager's PC does not bind in any of the two organizational forms.

Before we turn towards the welfare implications, however, we turn towards a brief discussion of first-best effort. First-best effort maximizes total surplus. For the second stage this implies that the manager should exert effort $\left(e_{M}=1\right)$ if $y_{1}=0$ and

$$
\pi+\theta_{W}+\theta_{M}-c \geq 0
$$

and $e_{M}=0$ otherwise. Notice that $A 1$ implies that the above condition holds. Also, the condition for the worker to exert effort $\left(e_{W}=1\right)$ in the first stage is $\pi+\theta_{W}+\theta_{M}-1 \geq 0$, and this is implied by the above condition as by assumption $c \geq 1$.

Not-for-profits commit the manager to no effort in our model because a share of profits $(1-\alpha) \pi$ cannot be captured by him. The first question is whether the share of profit that is lost to the manager is a deadweight loss (as in Glaeser and Shleifer, 2001), because, for example, he consumes it in the form of perks even though he would have preferred to have it in the form of cash, or whether it is redistributed towards the beneficiary of the project (as in Easly and O'Hara, 1983). If we assume the former, then choosing not-for-profits over for-profits will always decrease welfare. This is because the effort allocation does not change but not-for-profits waste resources by making it harder for the manager to capture the profit.

If the profit share $\left(1-\alpha^{*}\right) \pi$ is redistributed and not wasted, both organizational forms are equivalent in terms of welfare. To see this, note that all that matters for welfare in this case is who exerts effort. In both the for-profit and the not-for-profit the manager pays the worker an efficiency wage so that the worker does supply effort, and, therefore, the cost of production is one. For-profit and not-for-profit are therefore equivalent in terms 
of welfare. The only difference between the organizational forms is that the not-for-profit distributes more of the gains to the manager (and to a third party) and less to the worker. However, as we will see in the next section, the equivalence between for- and not-for-profits depends on our strong assumption that production is non-stochastic and it is sufficient for either the worker or the manager to supply effort for the project to go through.

\section{Extension: Stochastic Project Success}

The basic model presented above is based on a particular simplifying assumption removing which will add an extra effect that will go against the choice of not-for-profits. In particular, the assumption that the project always succeeds in case of worker effort reduces the welfare loss caused by manager commitment in the not-for-profit. If projects could fail despite worker effort then there is a positive role to be played by an active manager. To see this, assume that worker and manager effort lead to project success with a probability $h<1$. The ICC of the manager changes to:

$$
e_{M}^{*}\left(h, \alpha, \pi, c, \theta_{M}\right)=\left\{\begin{array}{ccc}
1 & \text { if } & h\left(\alpha \pi+\theta_{M}\right) \geq c \\
0 & \text { otherwise }
\end{array} .\right.
$$

From the ICC we can see immediately that the $\alpha^{*}$ that commits the manager to no effort is now

$$
\alpha^{*}=\frac{\frac{c}{h}-\theta_{M}}{\pi}
$$

which implies that assumption $A 1$ has to be modified to

$$
\text { Assumption } A 3: \pi \geq \frac{c}{h}-\theta_{M} \geq 0 \text {. }
$$

We derive the two efficiency wages in the appendix, they are

$$
w^{N P}=A\left(1-h \theta_{W}\right)
$$


for the not-for-profit and

$$
w^{F P}=A\left(1-h \theta_{W}\right)+(A h-1) h \theta_{W}
$$

for the for-profit, where $A \equiv \frac{1+(1-\rho) \beta}{\beta}$ as before.

First note, that the for-profit wage can now actually be lower than the not-for-profit wage if $A h<1$. This is because the worker benefits from being employed in a company that has a motivated manager even if the worker exerts effort himself. If $h$ is relatively small this factor weighs more heavily. Intuitively, an increasing failure rate $1-h$ increases the chance that the manager has to exert effort despite worker effort. This additional benefit is reflected in efficiency wages. In order to make not-for-profit dominance possible we need to assume that

\section{Assumption $A 4: A h \geq 1$}

so that $w^{F P} \geq w^{N P}$. For non-negativity of wages it then suffices to assume that $\theta_{W}<\frac{1}{h}$.

We discuss the manager PCs in the appendix. As before, in order for the not-for-profit to be feasible we need to assume that

$$
\text { Assumption } A 5: c \geq \frac{h\left(\pi+\theta_{M}\right)}{2} \text {. }
$$

Given these assumptions it is still possible that the not-for-profit is chosen by the manager. However, this can only be the case if the wage gains compensate the manager not only for lost profits but also for a loss in productivity. To see this, note that the manager prefers the not-for-profit if

$$
\begin{aligned}
& h\left(\alpha^{*} \pi+\theta_{M}\right)-w^{N P} \\
\geq & h\left(\pi+\theta_{M}\right)-w^{F P}+(1-h)\left[h\left(\pi+\theta_{M}\right)-c\right] .
\end{aligned}
$$

where the third term on the right-hand side represents the productivity benefit for the manager. If the project is about to fail (with probability $1-h)$ the manager in the for-profit can intervene. The following proposition 
then characterizes the conditions under which not-for-profits will be chosen:

Proposition 4 Assume that A3, A4 and A5 hold. The manager prefers the not-for-profit to the for-profit if

$$
\theta_{W} \geq \max \left(\frac{2-h}{(A h-1) h}\left(h\left(\pi+\theta_{M}\right)-c\right), \frac{1}{h}\left(1+\frac{h\left(\pi+\theta_{M}\right)-2 c}{A}\right)\right) .
$$

Proof. See the appendix.

Proposition 4 follows proposition 1 closely in the intuition. It states that not-for-profits can be preferred if worker intrinsic motivation is large compared to the benefits of project success.

The efficiency gain in the for-profit also makes for-profit status more attractive to the worker because the average provision rate is higher under that organizational form. Hence, for-profits dominate not-for-profits in terms of welfare even if the not-for-profit does not waste resources (i.e., the fraction $1-\alpha^{*}$ goes to third parties). To see this note that welfare under a for-profit is higher if

$$
\begin{aligned}
& h\left(\pi+\theta_{M}+\theta_{W}\right)-1+(1-h)\left(h\left(\pi+\theta_{M}+\theta_{W}\right)-c\right) \\
> & h\left(\pi+\theta_{M}+\theta_{W}\right)-1
\end{aligned}
$$

where the left-hand-side displays welfare under a for-profit and the righthand side is the welfare under a not-for-profit. By assumption $A 2$ this is always satisfied because $h\left(\pi+\theta_{M}+\theta_{W}\right)>c$.

In summary, our analysis above offers an interesting insight concerning the choice of not-for-profit status. Even if not-for-profits may yield lower expected surplus than for-profits, they might be chosen because of the rent extraction (i.e., paying the worker low wages) vs. efficiency trade-off that the manager faces. Even if it is socially efficient for both the worker and the manager to supply effort, the manager might want to tie his hands behind his back and commit not to supply effort if the need arises, in order to relax the worker's ICC. 


\section{Discussion}

Our analysis suggests that organizational choice between for-profits and notfor-profits would depend on, among other things, the relative scarcity of workers and managers. In particular, the abundance of motivated labor in some sectors may lead to the rise of not-for-profit organizations. Figure 2 provides a crude look at the existing cross-country evidence regarding the connection between not-for-profit (paid) employment and unemployment rates. ${ }^{19}$ For comparability we only focus on OECD countries. The graph shows a suggestive pattern with respect to groups of countries. Countries with very low unemployment rates (Sweden, Norway, Japan and Finland) also feature the least employment in not-for-profit firms. Most European continental countries as well as Australia, the US and UK feature both higher unemployment rates and higher not-for-profit employment. This pattern is only broken by Spain and Italy which feature both higher unemployment and low not-for-profit involvement. ${ }^{20}$ Clearly we cannot infer anything causal from this correlation, but it does suggest that with richer data macroeconomic factors such as unemployment rates (as well as institutional factors like the regulatory regime) might be useful in understanding the prevalence of not-for-profits. Our argument is, for example, consistent with some of the data presented in Mocan and Tekin (2003). Their evidence on worker selection show that weak labor market participants like Blacks and Hispanics are overrepresented in not-for-profits. While this could be driven by factors such as not-for-profits are less likely to discriminate, it is also consistent with our model.

More generally, our finding that labor market conditions affect organizational choice is relevant for empirical analysis as it suggests that measures of labor market slackness (for specific worker characteristics) might be an important omitted variable in studies that look at the effect of not-for-profit status on wages and labor donations. For example, unemployment is most

\footnotetext{
${ }^{19}$ Not-for-profit employment data (1991-1996) is from Salamon (1999). Unemployment rates (1990) are from the the CIA World Factbook.

${ }^{20}$ Dropping the three countries with double-digit unemployment makes the correlation significant at $5 \%$ level.
} 
likely correlated with typical dependent variables like wages (negative correlation) and labor donations (positive correlation) and might therefore bias the coefficient on not-for-profit status upwards.

\section{Conclusion}

In this paper we re-examine the labor donation theory of not-for-profits based on free-riding developed by Francois (2000, 2003). We embed the choice of for-profits vs. not-for-profits in a labor market setting where firms and workers match endogenously. We show that motivated workers are better off working in a for-profit firm compared to a not-for-profit firm. We show that if firms had to compete for workers not-for-profit firms would be competed out by for-profit firms. As a result we conclude that the reason for the existence of not-for-profit organizations may be because of the excess supply of motivated workers that make the non-profit form more attractive to managers. We also show that, assuming both organizational forms are feasible, for-profits welfare dominate not-for-profits, and strictly so, if production involves some uncertainty.

\section{Appendix}

\section{A Efficiency Wage}

The worker is assumed to be infinitely lived. If the worker is employed and exerts effort, she is not fired, and receives the present value of

$$
\begin{aligned}
E & =\theta_{W}+w-1+\beta E \\
& =\frac{\theta_{W}+w-1}{1-\beta} .
\end{aligned}
$$

We assume here that the worker is fired with certainty if she shirks and remains unemployed with probability $\rho$ once she is in that state. Unemployment benefits are normalized to 0 . Also, we assume that workers do not observe any activity within firms if they are unemployed, in particular, 
whether or not the public good is provided, and who supplies the effort. ${ }^{21}$ Therefore, if unemployed, the worker earns a present value of

$$
U=0+\beta(\rho U+(1-\rho) E) .
$$

This simplifies to

$$
\begin{aligned}
U & =\frac{\beta(1-\rho)}{1-\beta \rho} E \\
& =\frac{\beta(1-\rho)}{1-\beta \rho} \frac{\theta_{W}+w-1}{1-\beta}
\end{aligned}
$$

where we inserted the present value of employment with effort.

If the worker shirks she is caught with certainty, and her present value of utility is

$$
S=w+e_{M}^{*} \theta_{W}+\beta U
$$

The dependence on $e_{M}^{*}$ reflects the assumption that the manager cannot immediately replace a worker if she is fired, and will have to supply effort himself for that period.

The worker exerts effort if

$$
E \geq S
$$

or

$$
\frac{\theta_{W}+w-1}{1-\beta} \geq w+e_{M}^{*} \theta_{W}+\beta^{2} \frac{(1-\rho)}{1-\beta \rho} \frac{\theta_{W}+w-1}{1-\beta}
$$

Equation (2) follows immediately.

\section{B Proof of Proposition 1}

The manager prefers the not-for-profit to a for-profit if

$$
\alpha^{*} \pi+\theta_{M}-w^{N P} \geq \pi+\theta_{M}-w^{F P} .
$$

\footnotetext{
${ }^{21}$ This is similar to what Francois (2003) assumes. The results do not change qualitatively if we allow the unemployed workers to continue to receive utility from public goods provided in the firms from which they got fired.
} 
Given $A 1, \alpha^{*}$ lies between zero and 1 . Inserting $\alpha^{*}=\frac{c-\theta_{M}}{\pi}$ and rearranging, we get:

$$
w^{F P}-w^{N P} \geq \pi+\theta_{M}-c .
$$

Inserting $w^{F P}$ and $w^{N P}$ we get:

$$
A-\theta_{W}-A\left(1-\theta_{W}\right) \geq \pi+\theta_{M}-c
$$

or

$$
\theta_{W} \geq \frac{\pi+\theta_{M}-c}{A-1}
$$

Also, the condition for not-for-profits to satisfy the manager's PC is, rewriting (6):

$$
\theta_{W} \geq 1+\frac{\pi+\theta_{M}-2 c}{A}
$$

Given $A 2$ this condition is consistent with $\theta_{W} \leq 1$. The above two conditions can be combined as (8). The worker prefers the not-for-profit if

$$
\theta_{W}+w^{N P}>\theta_{W}+w^{F P}
$$

which, given Lemma 1 is never the case. This completes the proof.

\section{Proof of Proposition 3}

The relevant choice for the manager is between working alone and setting up a not-for-profit. Therefore, the relevant condition combines the condition for a not-for-profit to be chosen over autarchy, and for-profits not satisfying the manager's PC, i.e., rewriting inequalities (6) and (7) in terms of $\theta_{W}$ and combining them.

\section{Wages with Stochastic Success}

With effort the worker's utility is 


$$
\begin{aligned}
E & =h \theta_{W}+(1-h) p \theta_{W}+w-1+\beta E \\
& =\frac{h \theta_{W}+(1-h) p \theta_{W}+w-1}{1-\beta} .
\end{aligned}
$$

The unemployed worker has an expected utility of

$$
\begin{aligned}
U & =0+\beta(\rho U+(1-\rho) E) \\
& =\frac{\beta(1-\rho)}{1-\beta \rho} \frac{h \theta_{W}+(1-h) p \theta_{W}+w-1}{1-\beta} .
\end{aligned}
$$

If the worker shirks her present value of utility is

$$
S=w+p \theta_{W}+\beta U
$$

The worker exerts effort if

$$
E \geq S
$$

or

$\frac{h \theta_{W}+(1-h) p \theta_{W}+w-1}{1-\beta} \geq w+p \theta_{W}+\beta^{2} \frac{(1-\rho)}{1-\beta \rho} \frac{h \theta_{W}+(1-h) p \theta_{W}+w-1}{1-\beta}$.

Simplifying, and solving for $w$ we get:

$$
w \geq\left(\frac{1+(1-\rho) \beta}{\beta}\right)\left(1-h \theta_{W}+\left(h-\frac{\beta}{1+(1-\rho) \beta}\right) p \theta_{W}\right)
$$

Therefore, the wage in the not-for-profit is:

$$
w \geq A\left(1-h \theta_{W}\right) .
$$

In the for-profit, it is:

$$
w \geq A\left(1-h \theta_{W}+\left(h-\frac{1}{A}\right) h \theta_{W}\right)
$$


which simplifies to the condition given in the text.

\section{E Manager PCs with Stochastic Success}

The manager's PC in the for-profit is

$$
h\left(\pi+\theta_{M}\right)-w^{F P}+(1-h)\left(h\left(\pi+\theta_{M}\right)-c\right) \geq h\left(\pi+\theta_{M}\right)-c
$$

or

$$
c \geq \frac{h(1-h)\left(\pi+\theta_{M}\right)+A-(A(1-h)+1) h \theta_{W}}{h} .
$$

In the not-for-profit, it is:

$$
h\left(\alpha^{*} \pi+\theta_{M}\right)-w^{N P} \geq h\left(\pi+\theta_{M}\right)-c
$$

or

$$
c \geq \frac{h\left(\pi+\theta_{M}\right)+A\left(1-h \theta_{W}\right)}{2} .
$$

Given our assumption of non-negative wages $\left(h \theta_{W} \leq 1\right)$ we need to assume that

$$
c \geq \frac{h\left(\pi+\theta_{M}\right)}{2}
$$

\section{F Proof of Proposition 4}

The proof for Proposition 4 is similar to the proof of Proposition 2. The condition for the not-for-profit is preferred is:

$$
\begin{aligned}
& h\left(\alpha^{*} \pi+\theta_{M}\right)-w^{N P} \\
\geq & h\left(\pi+\theta_{M}\right)-w^{F P}+(1-h)\left(h\left(\pi+\theta_{M}\right)-c\right) .
\end{aligned}
$$

Plugging in

$$
\alpha^{*}=\frac{\frac{c}{h}-\theta_{M}}{\pi}
$$


and the wages, we get:

$$
\begin{aligned}
& c-\left(\frac{1+(1-\rho) \beta}{\beta}\right)\left(1-h \theta_{W}\right) \\
\geq & h\left(\pi+\theta_{M}\right)-\left(\frac{1+(1-\rho) \beta}{\beta}\right)\left(1-h \theta_{W}+\left(h-\frac{\beta}{1+(1-\rho) \beta}\right) h \theta_{W}\right) \\
& +(1-h)\left(h\left(\pi+\theta_{M}\right)-c\right) .
\end{aligned}
$$

After rearranging and with $A=\frac{1+(1-\rho) \beta}{\beta}$ we get:

$$
\theta_{W} \geq \frac{2-h}{(A h-1) h}\left(h\left(\pi+\theta_{M}\right)-c\right) .
$$

The PC of the manager in the not-for-profit is:

$$
h\left(\alpha^{*} \pi+\theta_{M}\right)-w^{N P} \geq h\left(\pi+\theta_{M}\right)-c .
$$

This can be rewritten as:

$$
c-A\left(1-h \theta_{W}\right) \geq h\left(\pi+\theta_{M}\right)-c
$$

or,

$$
\theta_{W} \geq \frac{1}{h}\left(1+\frac{h\left(\pi+\theta_{M}\right)-2 c}{A}\right)
$$

\section{G Continuous Effort and Incentive Schemes}

We show here that our key results are not driven by either our assumption of continuous effort nor our assumptions about contractibility. Let us assume that intermediate output in contractible so that a wage can be paid that is contingent on it.

We assume, as before, that manager and worker move consecutively. First the worker chooses $e_{W} \in[0,1]$ then, after observing project success or failure, the manager chooses $e_{M} \in[0,1]$. The probability of project success 
in each stage is $e_{i}, i=M, W$. We assume the following effort cost function:

$$
C\left(e_{i}\right)=\frac{c_{i}}{2} e_{i}^{2}, i=M, W
$$

where $c_{W}=1$ and $c_{M}=c \geq 1$.

Benefits from project success are similar to the case of discrete effort. This implies that the manager exerts effort

$$
e_{M}^{*}=\min \left\{\frac{\alpha \pi+\theta_{M}}{c}, 1\right\}
$$

in the second stage. We will have an interior solution if $\frac{\alpha \pi+\theta_{M}}{c} \leq 1$ or, $\alpha \leq \frac{c-\theta_{M}}{\pi}$. If $\frac{\alpha \pi+\theta_{M}}{c}>1$, a reduction in $\alpha$ has no effect on manager effort. In order to keep the analysis simple we therefore assume an interior solution. A sufficient condition for this is $c>\pi+\theta_{M}$.

The worker maximizes

$$
E U_{W}=e_{W}\left(w+\theta_{W}\right)+\left(1-e_{W}\right) e_{M}^{*} \theta_{W}-\frac{1}{2} e_{W}^{2}
$$

which has the following first-order-condition

$$
e_{W}^{*}=w+\left(1-e_{M}^{*}\right) \theta_{W} .
$$

Note, that this is exactly the effort crowding out we also observed in the previous worker ICC. Put differently, the not-for-profit status increases worker effort because it reduces manager effort

$$
\frac{\delta e_{W}^{*}}{\delta \alpha}=-\frac{\delta e_{M}^{*}}{\delta \alpha} \theta_{W}=-\frac{\pi}{c} \theta_{W}<0 .
$$

In order to show that a reduction in $\alpha$ reduces wages we have to solve for the optimal wage. Write manager expected utility

$$
E U_{M}=e_{W}^{*}\left(\alpha \pi-w+\theta_{M}\right)+\left(1-e_{W}^{*}\right)\left(e_{M}^{*}\left(\alpha \pi+\theta_{M}\right)-\frac{c}{2} e_{M}^{* 2}\right)
$$

after plugging in $e_{W}^{*}$ and $e_{M}^{*}$ and some simplification we get 


$$
\begin{aligned}
E U_{M}= & \left(w+\left(1-\frac{\alpha \pi+\theta_{M}}{c}\right) \theta_{W}\right)\left(\alpha \pi-w+\theta_{M}\right) \\
& +\left(1-\left(w+\left(1-\frac{\alpha \pi+\theta_{M}}{c}\right) \theta_{W}\right)\right)\left(\frac{\left(\alpha \pi+\theta_{M}\right)^{2}}{2 c}\right)
\end{aligned}
$$

and the first order condition for the wage yields

$$
w=\frac{\left(\alpha \pi+\theta_{M}\right)-\left(1-\frac{\alpha \pi+\theta_{M}}{c}\right) \theta_{W}-\left(\frac{\left(\alpha \pi+\theta_{M}\right)^{2}}{2 c}\right)}{2} .
$$

The effect of $\alpha$ on wages is then

$$
\frac{\delta w}{\delta \alpha}=\frac{\pi+\frac{\pi}{c} \theta_{W}-\left(\frac{\left(\alpha \pi+\theta_{M}\right) \pi}{c}\right)}{2} .
$$

For not-for-profits to be ever chosen, we must have $\frac{\delta w}{\delta \alpha}>0$ at $\alpha=1$. This is the case if:

$$
\theta_{W}>\pi+\theta_{M}-c
$$

which follows directly from the sufficient condition for an interior solution for the manager's choice of effort. 
Acknowledgements: We thank Tim Besley, Konrad Burchardi, Manishita Dass, Patrick Francois, Paul Grout, Gilat Levy, Rocco Macchiavello, Sarah Sandford, and several seminar audiences for helpful feedback. We are responsible for all remaining errors.

\section{References}

[1] Benabou, R., Tirole, J., 2006. Incentives and Prosocial Behavior. American Economic Review. 96, 652-1678.

[2] Besley, T., Ghatak, M., 2005. Competition and Incentives with Motivated Agents.. American Economic Review. 95, 616-636.

[3] Bilodeau, M., Slivinski, A., 2004. Rational Nonprofit Entrepreneurship. Journal of Economics \& Management Strategy. 7, 551 - 571.

[4] Bornstein, D., 2004. How to Change the World: Social Entrepreneurs and the Power of New Ideas, Oxford University Press.

[5] Clark, J., 2007. Voluntary Sector Skill Survey 2007, England. The UK Workforce Hub.

[6] Delfgaauw, J., Dur, R., 2007. Signaling and Screening of Workers' Motivation. Journal of Economic Behaviour and Organization. 62, 605-624.

[7] Easley, D., O'Hara, M., 1983. The Economic Role of the Nonprofit Firm. The Bell Journal of Economics. 14, 531-538.

[8] Fama, E., Jensen, M., 1983. Agency Problems and Residual Claims. Journal of Law and Economics. 26, 327-50.

[9] Francois, P., 2000. Public Service Motivation' as an Argument for Government Provision. Journal of Public Economics. 78, 275-299.

[10] Francois, P., 2003. Not-for-Profit Provision of Public Services. Economic Journal. 113, C53-C6. 
[11] Francois, P., Vlassopoulos, M., 2008. Pro-social Motivation and the Delivery of Social Services. CESifo Economic Studies, 1-33.

[12] Glaeser, E., Shleifer, A., 2001. Not-for-profit Entrepreneurs. Journal of Public Economics. 81, 99-115.

[13] Gregg, P., Grout, P., Ratcliffe, A., Smith, S., Windmeijer, F., 2008. How Important is Pro-social Behaviour in the Delivery of Public Services?. CMPO Working Paper Series. No. 08/197.

[14] Hansmann, H., 1980. The Role of Nonprofit Enterprise. Yale Law Journal. $89,835-901$.

[15] Holmstrom, B., Milgrom, P., 1991. Multitask Principal-Agent Analyses: Incentive Contracts, Asset Ownership, and Job Design. Journal of Law, Economics and Organization. 7, 24-52.

[16] Lakdawalla, D., Philipson, T., 2006. The Nonprofit Sector and Industry Performance. Journal of Public Economics. 90, 1681-1698.

[17] Leete, L., 2001. Whither the Nonprofit Wage Differential? Estimates from the 1990 Census. Journal of Labor Economics. 19, 136-170.

[18] Martin, R. L., and S. Osberg, 2007: Social Entrepreneurship: The Case for Definition. Stanford Social Innovation Review, Spring, pp. 29-39.

[19] Macchiavello, R., 2008: Public Sector Motivation and Development Failures. Journal of Development Economics, 86-1: pp. 201-213.

[20] Mocan, N., Tekin, E., 2003. Nonprofit Sector and Part-time Work: An Analysis of Employer-Employee Matched Data on Child Care Workers. Review of Economics and Statistics. 85, 38-50.

[21] Preston, A. E., 1989: The Nonprofit Worker in a For-profit World. Journal of Labor Economics. 7, 438-463.

[22] Rose-Ackerman, S., 1996. Altruism, Nonprofits and Economic Theory. Journal of Economic Literature, 34, 701-728. 
[23] Rowat, C., Seabright, P., 2006. Intermediation by Aid Agencies. Journal of Development Economics. 79, 469-491.

[24] Salamon, L., Anheier, H. K., List, R., Toepler, S., Sokolowski, S. W. and Associates, 1999. Global Civil Society: Dimensions of the Nonprofit Sector. The Johns Hopkins Center for Civil Society Studies, Baltimore.

[25] Salamon, L., Haddock, M. A., Sokolowski, S. W., Tice, H., 2007. Measuring Civil Society and Volunteering: Initial Findings from Implementation of he UN Handbook on Nonprofit Institutions. Working Paper No. 23. The Johns Hopkins Center for Civil Society Studies, Baltimore.

[26] Vlassopoulos, M. 2009: Quality, reputation and the choice of organizational form. Journal of Economic Behavior \& Organization, 71(2), pp. $515-527$. 


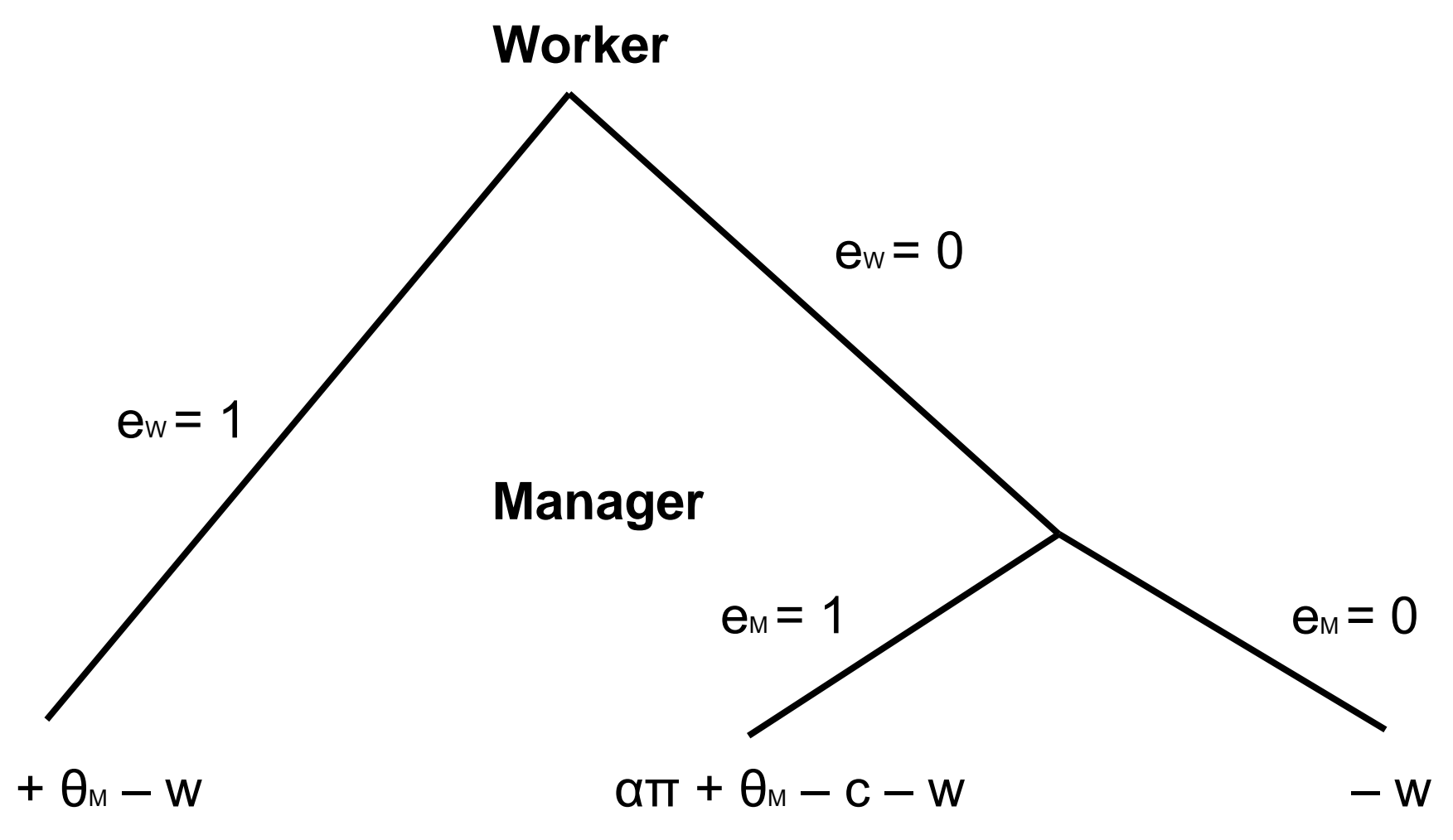

Worker:

$\theta_{w}-1+w$

$\theta_{w}+w$

W

Figure 1: Game Tree 
Figure 2:Not-for-profit employment and unemployment rates in OECD countries

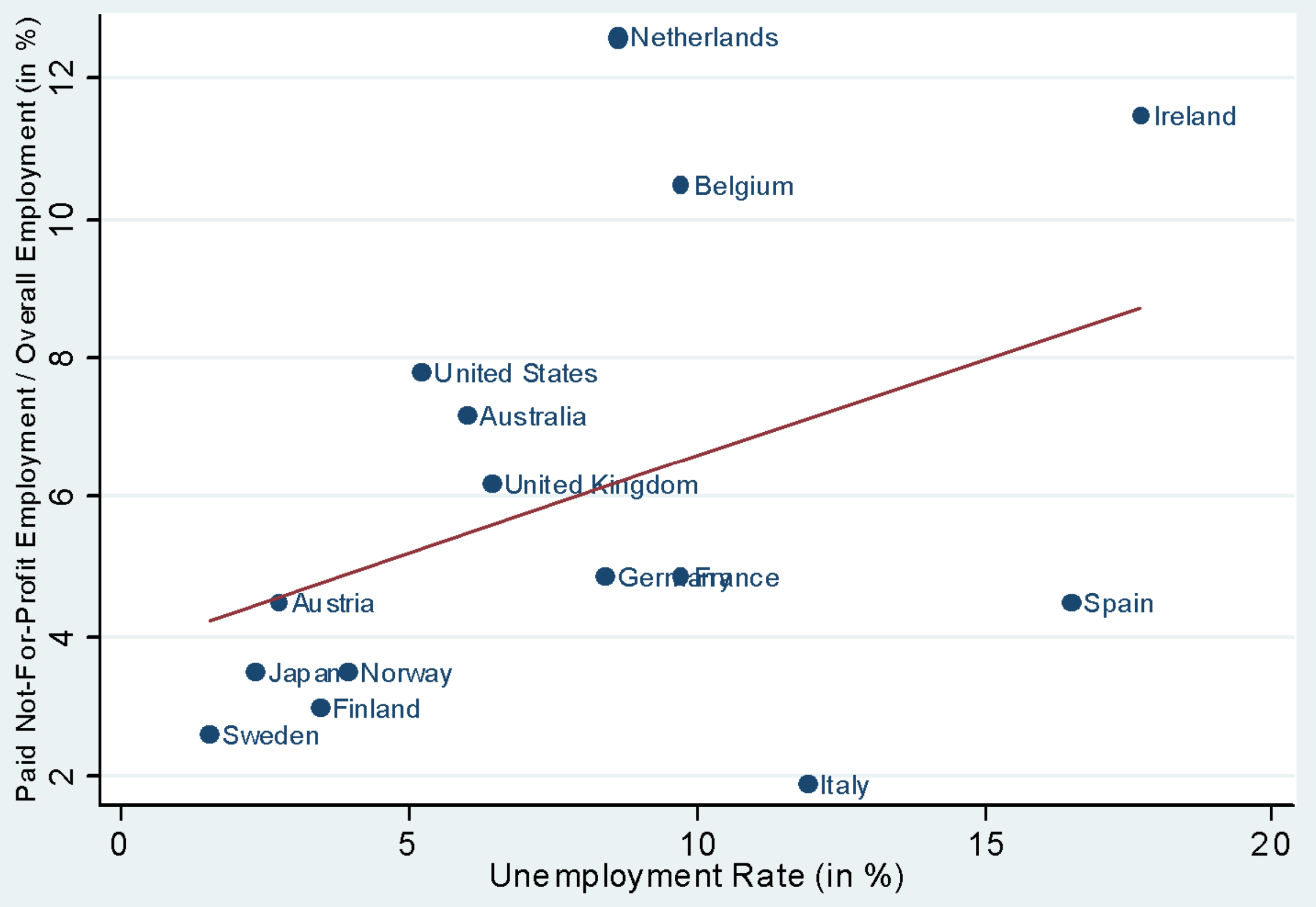

